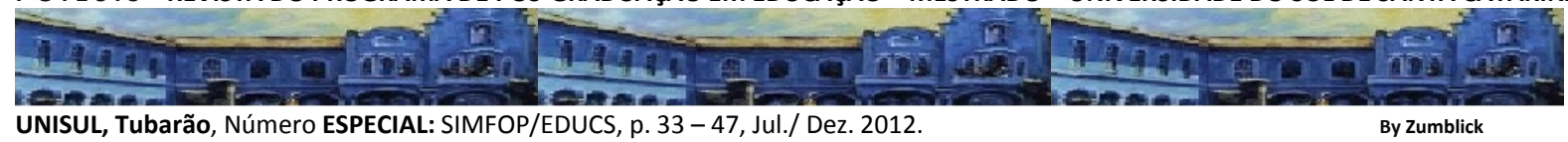

\title{
MOÇAS INVADINDO O ESPAÇO MASCULINO: A ESCOLA TÉCNICA DA SOCIEDADE DE ASSISTÊNCIA AOS TRABALHADORES DO CARVÃO NOS ANOS DE 1970
}

\author{
Ms Jucélia da Silva Abel ${ }^{1}$ \\ Dra Giani Rabelo²
}

\section{RESUMO}

A Sociedade de Assistência aos Trabalhadores do Carvão (SATC) foi criada em 1959, por iniciativa da Indústria de Extração de Carvão Mineral da Região Carbonífera de Santa Catarina, para atender os trabalhadores do carvão, tanto no campo assistencial, quanto no campo de assistência educacional, para qualificar mão de obra para o mercado de trabalho. Somente em 1975 foi que a Escola abriu suas portas para a inserção de mulheres, num espaço, até então, predominantemente masculino. Este estudo objetivou investigar a presença das primeiras alunas que ingressaram nos cursos técnicos da SATC no início da década de 1970, a partir das memórias de quatro ex-alunas, de três gestores e um professor, bem como dos documentos oficiais do acervo da SATC e dos recortes de jornais da época.

Palavras-chave: Escola Técnica; Gênero; Memória.

GIRLS INVADIND THE MALE SPACE: TECHNICAL SCHOOL OF SOCIETY OF ASSISTENCE OF COAL WORKERS IN YEARS 1970s

\begin{abstract}
The Sociedade de Assistência aos Trabalhadores do Carvão - SATC (Society for Assistance for Coal Workers and its acronym in Portuguese) was created in 1959, by an initiative of the Industry of Coal Extraction in Coal Region in Santa Catarina, in order to attend the coal workers both in assistance field and in education to qualify worker to the Market. Only in 1975 the School opened its doors to the insertion of women in a space predominantly male until time. This study aimed to investigate the presence of first female students in Technical Courses of SATC in the early 1970s from memories of four alumni, three managers and one professor, as well as official documents from SATC collection and from newspapers of that time.
\end{abstract}

Key-words: Technical School; Gender; Memory.

A Sociedade de Assistência aos Trabalhadores do Carvão - SATC foi criada em 1959, por iniciativa da Indústria de Extração de Carvão Mineral da Região Carbonífera de Santa Catarina, para atender os trabalhadores do carvão, tanto no campo assistencial, com o objetivo de amenizar os problemas decorrentes do crescente desenvolvimento na região, quanto no campo de assistência educacional, para qualificar mão de obra para o mercado de trabalho.

\footnotetext{
${ }^{1}$ Mestre pelo Programa de Pós-Graduação em Educação em Educação da Universidade do Extremo Sul Catarinense, UNESC. E- mail: <juceliaabel@hotmail.com>.

${ }^{2}$ Professora Doutora do Programa de Pós-Graduação em Educação da Universidade do Extremo Sul Catarinense, UNESC. E- mail: <gra@unesc.net>.
} 
Em 1975 a escola criou o curso Técnico de Mecânica e abriu as portas para o ingresso de moças, num espaço até então predominantemente masculino, o que instigou saber: Como as relações de gênero se configuraram nas narrativas das primeiras alunas que ingressaram nos cursos técnicos da SATC no início da década de 1970?

Com o objetivo de desdobrar essa problemática, algumas questões foram investigadas: Quais as motivações das primeiras alunas para o ingresso na Escola Técnica? Como as alunas se percebiam na relação com os seus colegas e professores/as? Quais regras foram instituídas na escola com a inserção das mulheres? O que levou os gestores da SATC a decidirem pela inserção das mulheres nos cursos técnicos ofertados a partir de 1970? Como os documentos oficiais da SATC registraram esse acontecimento? O que fundamentou esta ação institucional? Quais os discursos que sustentaram esta política de inserção das mulheres?

Investigar a inserção das primeiras mulheres nos cursos técnicos da SATC, numa perspectiva histórica e de gênero, teve como principal objetivo dar visibilidade às questões enfrentadas por elas naquele momento histórico, tendo como lócus a Escola Técnica “Oswaldo Pinto da Veiga".

Estudar o conceito de gênero enquanto categoria útil de análise da história das mulheres reforça a importância dos estudos de gênero para a sociedade e, neste caso, para o campo educacional.

Numa abordagem qualitativa, no intuito de reconstruir o passado vivenciado a partir das narrativas das primeiras alunas dos cursos técnicos da SATC, foram analisadas as lembranças desses sujeitos. Ao mesclarem-se, o passado e o presente dão à lembrança um sentido mais real. Recuperar lembranças é o movimento da memória, que é livre e espontânea. Segundo Kenski, "na recuperação da memória por meio da língua, da fala e da escrita, o sujeito conta uma história. Uma história cheia de memórias, mas cheia também de revisões, de recuperações, de construções atuais daquilo que foi o passado" (KENSKI,1995, p. 150).

Como recurso metodológico para trabalhar com as memórias das primeiras alunas dos cursos técnicos da SATC no início da década de 1970, a História Oral foi utilizada. Para Meihy (2005, p. 17), “a história oral é um recurso moderno usado para elaboração de documentos, arquivamento e estudos referentes à experiência social de pessoas e de grupos. Ela é sempre uma história de tempo presente e é reconhecida como história viva". Para o autor, existem três modalidades de história oral: história oral de vida, história oral temática e tradição oral. (MEIHY, 2005). 
Neste trabalho de pesquisa, a modalidade escolhida e utilizada foi a história oral temática, uma vez que, para atingir o objetivo, os sujeitos deste estudo contribuíram com seus depoimentos sobre um determinado tempo e experiência. Nove alunas matricularam-se no referido curso, sendo que destas, seis o concluíram - quatro no ano de 1976, uma no ano de 1977 e uma no ano de 1978. As ex-alunas, sujeitos desta pesquisa, foram escolhidas a partir de um levantamento realizado junto aos documentos oficiais da SATC, que registram as matrículas e os concluintes de cursos. Estes documentos proveram dados sobre as alunas que concluíram o Curso de Mecânica, orientado para o Desenho Mecânico.

Com o intuito de entrevistá-las, foi elaborado um roteiro semiestruturado. Além das quatro ex-alunas, também foi entrevistado, com utilização dos mesmos procedimentos, um dos atuais gestores da instituição, que à época do ingresso das primeiras alunas na Escola Técnica "General Osvaldo Pinto da Veiga" ocupava o cargo de Coordenador dos Cursos Técnicos. Na ocasião, ele acompanhou o processo de inserção das primeiras mulheres nos cursos técnicos. Foi entrevistada, também, a Coordenadora Geral do Ensino Técnico e Médio, que ingressou na instituição no mesmo ano das primeiras alunas, ocupando o cargo de Auxiliar de Secretaria, além de um Conselheiro da época e um Professor que lecionava a disciplina de Desenho Técnico.

Nesta investigação foi buscado, numa perspectiva histórica, conhecer o processo que estruturou a região carbonífera, sustentando ora o crescimento econômico e social, ora as crises. Neste contexto, foram investigadas as necessidades que fizeram com que os investidores do carvão da região sul catarinense criassem uma Escola Técnica Industrial para preparar mão de obra qualificada dentro de um padrão, dito pelos mesmos, como o ideal.

Entender o processo do ensino profissionalizante no Brasil também se fez necessário para este estudo, que objetivou entender como se deu a inserção das primeiras mulheres no ensino técnico de uma escola direcionada exclusivamente aos homens.

Iniciamos apresentando a criação da SATC no contexto do complexo carbonífero, apresentando a SATC no contexto da indústria carbonífera e do ensino profissionalizante, levantando a história da indústria carbonífera, a exploração do carvão, o crescimento da população de Criciúma, as vilas operárias e seus problemas sociais, discorrendo, então, sobre a criação da SATC e o cenário do ensino profissionalizante brasileiro.

Posteriormente é apresentada, historicamente, como se deu, no Brasil, a inserção das mulheres na educação formal e, principalmente, na educação profissionalizante a fim de entender 
quais discursos atravessaram o processo que levou a SATC a abrir as portas de seus cursos técnicos para as mulheres, e a inserção feminina no mercado de trabalho.

Por fim, expõe-se a problematização do objeto de estudo - as relações de gênero, relatando como aconteceu a escolha pelo curso técnico, a adequação da escola para receber as alunas, a relação das mesmas com gestores e alunos, as mudanças das regras disciplinares e transgressões, evidenciadas por meio das entrevistas realizadas com as alunas e demais entrevistados. Tais análises são subsidiadas por estudos das relações de gênero e de poder.

A exploração do carvão mineral ocasionou o crescimento da região sul de Santa Catarina e da população de Criciúma, devido à chegada de trabalhadores para as indústrias carboníferas. Esse crescimento e avanço, próprios da modernidade, chegaram à cidade acompanhados de problemas sociais.

Num primeiro momento, as mineradoras construíram vilas operárias para abrigar as famílias que se instalavam na região para trabalharem nas minas, porém, as condições eram precárias, principalmente no que dizia respeito à higiene e saúde. Com o propósito de tornar os filhos/as dos operários, saudáveis, produtivos e disciplinados, e como o cenário das vilas operárias em nada contribuía, os mineradores fundaram, em 2 de maio de 1959, a Sociedade de Assistência aos Trabalhadores do Carvão - SATC, fadada a tornar-se a grande obra assistencial e educacional do Estado de Santa Catarina.

No setor de assistência social ficou registrado que a SATC teria, como finalidade prioritária, prestar assistência hospitalar em casos clínicos, prover assistência farmacêutica, dentária, educacional-técnica, habitacional, alimentar, recreativa e outras, aos empregados da indústria extrativa do carvão em Santa Catarina e aos que exerciam atividades correlatas à mesma indústria e suas famílias. Para tanto, firmaram convênio com a Congregação das Pequenas Irmãs da Divida Providência, que prestavam o chamado Serviço de Plantão, que compreendia visitas domiciliares, orientação sobre saúde, alimentação, higiene e o serviço de puericultura, onde acompanhavam as gestantes e crianças nos seus primeiros anos de vida.

Tal assistência contribuía para a formação de trabalhadores saudáveis e, consequentemente, mais produtivos, operário desejado pela indústria carbonífera.

No setor de assistência educacional, inicialmente, faziam a distribuição de bolsas de estudo aos filhos/as de mineiros em escolas da região. Em 1961 iniciou-se a construção da Escola Profissional Masculina, que foi concluída em 1963, tendo o nome alterado para Escola Industrial 
Masculina, que abriu vagas aos filhos de mineiros para qualificação profissional, nos cursos Industrial Básico e Aprendizagem Industrial em convênio com o SENAI.

A Escola Técnica "General Oswaldo Pinto da Veiga" foi fundada em um momento crucial para os donos das minas do carvão, em abril de 1963, uma vez que o setor, à medida que ia crescendo e se desenvolvendo, necessitava de mão de obra qualificada, do contrário, ficaria dependendo de mão de obra externa. Em seu projeto inicial, a assistência educacional seria para os filhos e filhas dos mineiros, entretanto, somente os homens foram contemplados, ficando para trás o projeto de educação doméstica que seria ofertado às mulheres.

Com ideário de formar mão de obra qualificada, disciplinada e obediente, em 1964, a SATC firmou convênio com a Ordem Religiosa de Educadores dos Irmãos Maristas, justificado pela necessidade de apoio pedagógico, bem como melhor preparação moral de seus alunos, o que vinha ao encontro do que se pretendia dos futuros operários das mineradoras: disciplina e obediência.

Essa preparação de mão de obra para as mineradoras remete ao objetivo do ensino profissionalizante no Brasil, que foi criado para as camadas mais pobres, primeiramente, para solucionar problemas sociais, posteriormente, para formação de força de trabalho. O Decreto no 7.566/1909 criou as escolas de aprendizagens e artífices, cuja missão era preparar cidadãos mais úteis à nação, inserindo-os na produção fabril.

Em 1931 foi criado o Conselho Nacional de Educação que, com o Decreto Federal no 20.158, estruturou o ensino profissionalizante. Contudo, somente em 1942 foi aprovado o conjunto de Leis Orgânicas do Ensino, por meio da Reforma Capanema, que alavancou o ensino profissionalizante. Neste mesmo ano foram criados o INEP, SENAI e o SENAC.

Após a decretação das Leis Orgânicas, o governo continuou a oferecer percursos diferenciados para as classes mais abastadas daquelas oferecidas às classes populares. Em 1950 a Lei Federal no 1.076 permitia que alunos ingressassem em cursos superiores mediante exames de disciplinas não estudadas no curso, e nem mesmo a Lei no 4.024/61 conseguiu superar a dualidade do ensino, permanecendo a divisão de trabalho, ou seja, formar profissionais para o trabalho e profissionais intelectuais.

A SATC, quando de sua criação, ajustou-se exatamente neste contexto de dualidade, preparando/qualificando mão de obra para a força de trabalho. A educação feminina e o acesso à escola formal aconteceram de maneira tímida no governo Imperial, sublinhando a elas uma 
educação voltada aos trabalhos manuais, referentes ao papel doméstico, visão esta evidenciada nos projetos iniciais da SATC.

Somente em 1827 o Estado Imperial assinou a lei que tratava da educação das mulheres, permitindo, então, que frequentassem a escola Elementar. Mesmo assim, tinha-se a ideia de que bastava uma base moral sólida e bons princípios para que fossem boas esposas e boas mães. A ideia hegemônica de que as mulheres não precisavam de muitos conhecimentos e informações limitava a aprendizagem.

Essa educação considerada ideal para o público feminino evidenciava uma forte desigualdade de gênero. Na transição do século XIX para o XX surgiram propostas e iniciativas para organizar a educação e ampliar o número de escolas. Tal transição foi marcada por muitas transformações sociais, políticas, econômicas e culturais, que possibilitaram o início de protestos feministas em busca de direitos, como a educação e a profissionalização.

Podemos dizer que esses protestos em busca de direitos à educação foram cobertos por resistências, principalmente da Igreja Católica, que condenava a ideia de misturar os sexos, chamado de coeducação, nas salas de aulas, e essa resistência em muito atrasou o ingresso das mulheres na educação.

Segundo Louro (1997), a educação feminina deveria ter uma sólida base cristã, pois para muitos, ela era o que se tinha de mais precioso em qualquer projeto educativo. 0 catolicismo era a referência em educação da época; mesmo com a separação da Igreja Católica do Estado, a moral religiosa era o mais indicado para a educação das mulheres. Para a Igreja, a mulher tinha a missão da maternidade e a representação da pureza.

Somente em 1971, com a Lei de Diretrizes e Bases no 5.692/71, foi modificada a estrutura do ensino brasileiro, ampliando-se a obrigatoriedade escolar para oito anos, ou seja, para faixa etária que vai dos sete aos quatorze anos de idade, tanto para meninos quanto para meninas. Essa lei estava fundamentada em dois princípios: continuidade e terminalidade. O primeiro oferecia conteúdo para uma base geral ampla, ocorrido nas séries do Primeiro Grau, para formação especial e habilitações profissionais, que se seguiria no Segundo Grau. E o segundo, oferecia uma formação que capacitava o aluno para o exercício de uma atividade, tanto no primeiro como no segundo grau.

E foi exatamente neste contexto da legislação educacional que a Escola Técnica da SATC abriu as portas para as primeiras alunas. Mesmo com as mudanças na Legislação e a abertura da 
Escola Formal para as mulheres, o contexto estava atravessado por barreiras e discursos que imprimiam a ideia de que as mulheres não precisavam aprender a ler e escrever.

A entrada das mulheres nos cursos profissionalizantes também foi marcada por restrições e barreiras, seguindo a mesma ideia da educação formal, pois a elas cabiam profissões que significassem uma continuidade da maternidade, como o Magistério, ideal para as mulheres, uma vez que poderiam trabalhar apenas um período, sobrando tempo para o cuidado da família e dos serviços domésticos.

Assim, o discurso da Igreja contribuía em muito para a discriminação das mulheres. A possibilidade de uma construção social e individual que levasse as mulheres ao crescimento pessoal e profissional era completamente repugnada.

Naquela época predominava, em Criciúma, uma hierarquia das diferenças de gênero. Mesmo com a inserção de mulheres no mercado de trabalho, poucas trabalhavam fora, expressão usada para o trabalho que não era o doméstico.

$\mathrm{Na}$ cidade predominavam as minas de carvão e os papéis sociais tradicionalmente atribuídos aos sexos no processo de formação das famílias mineiras. Os homens assumiam para si a exclusividade dos serviços denominados perigosos e bastante desgastantes fisicamente, que eram mais valorizados pela sociedade; já às mulheres, cabiam os serviços da casa, dos filhos, a preparação da alimentação da família, entre outros serviços que eram desvalorizados pela sociedade (CAROLA, 2002).

Para Louro (1996), tal ideário advém do discurso comum, baseado em pressupostos positivistas do século XIX, quando era considerada natural a caracterização da mulher como uma forma de complementar o homem. Este discurso predominou também no início da República, pois a função da mulher era, como mãe, formar os futuros homens. A eles cabiam questões públicas e, a elas, as questões domésticas.

Havia uma divisão sexual do trabalho socialmente construída. Até os anos de 1970 , as mulheres se concentravam nos cursos de Economia Doméstica e Normal, fazendo valer o discurso de que a modernização do país primava por formações diferentes para cada sexo e de que, para as mulheres, deveriam ser reservados os cursos que exigiam habilidades maternais e domésticas. A formação das mulheres no ensino profissionalizante trouxe consigo marcas profundas, que resultaram em uma inserção desigual das mulheres no mercado de trabalho formal.

Foi na década de 1970 que a entrada das mulheres no mercado de trabalho alavancou. Este processo também teve base na preponderância dos mesmos discursos que atravessaram sua 
inserção na educação, que impunha desigualdade de salário, dificuldades de promoção e preconceitos. O papel da mulher na sociedade, sua função social, suas rupturas, transformações e permanências fizeram parte da luta feminina traçada pela busca da igualdade de direitos.

A construção histórica dos papéis sociais atribuídos ao homem e à mulher promoveu uma desigualdade ao segmento feminino quanto às questões culturais, biológicas, políticas e econômicas, sendo que essa desigualdade foi justificada, muitas vezes, pela inferiorização do gênero feminino como característica natural. Um suposto determinismo biológico atribuído à mulher alicerça esta realidade, construindo-se uma condição de submissão e às mulheres foram relegadas as funções domésticas e uma total exclusão da vida pública, ficando, as mesmas, em situação social de dependência e subordinação ao sexo masculino.

Essa constatação remete ao conceito de gênero, que é, antes de tudo, uma construção histórica e social, cujas referências partem das representações sociais e culturais construídas a partir da diferença biológica de sexo. Se o feminino e o masculino são determinados pela cultura e pela sociedade, logo, essa desigualdade pode ser mudada.

Com a complexidade das relações humanas, o aparecimento de outras atividades que exigiam grande esforço físico e o surgimento das sociedades agrárias e pastoris, a figura masculina predominou sobre a feminina, que consolidou a instituição patriarcal. A mulher, então, passou a ser considerada como uma propriedade do marido, tendo como funções a reprodução da espécie, o cuidado da casa, a criação dos filhos, os trabalhos manuais, a produção de bens necessários e a subsistência da família. Isso leva a confirmar, portanto, que a desigualdade entre homens e mulheres é uma construção histórica e não natural (LUSTOSA, 2009).

Os discursos encontrados nos documentos e jornais da época assinalavam que a inserção das mulheres nos cursos técnicos da SATC fazia-se necessária, uma vez que o mercado de trabalho abria as portas para a mão de obra feminina,

A escola técnica General Osvaldo Pinto da Veiga, assinalando seus dez anos de funcionamento, anuncia para o ano de setenta e cinco, uma inovação das mais avassaladoras para toda a região sul de Sta. Catarina, que consiste na introdução de mulheres nos cursos profissionalizantes, destinados a atender as exigências do mercado de trabalho, principalmente, nos campos da indústria e da agricultura. Comentando o assunto, o professor Leo Uliano, disse que há bem pouco tempo atrás [sic] a mentalidade do povo não aceitava de forma alguma, a idéia de ver uma moça trabalhando em máquinas ou vestindo um macacão. Todavia, a infiltração gradativa do elemento feminino nos diversos campos de atividades, antes só admitido ao homem, vem quebrando o tabu (JORNAL TRIBUNA, 1974, p. 7). 
Esta nota demonstra a medida tomada como uma quebra de tabu. Entretanto, alguns termos utilizados estão carregados de discurso preconceituoso, como no caso de "infiltração gradativa do elemento feminino"; afinal, por que não a utilização de a "inserção gradativa das mulheres..."? Mas também havia o discurso de que, por não ter tido um número significativo de inscrições de alunos no ano anterior à entrada das mulheres, a escola, com algumas restrições, uma vez que defendia a tese de que o serviço nas minas era muito pesado para elas, abriu inscrições para as mulheres.

E foi esta ideia de serviço pesado e leve que definiu o curso de Mecânica opção para o desenho como ideal para receber as alunas, pois o desenho era considerado uma habilidade feminina.

Foram várias as motivações que levaram as primeiras alunas a ingressar na SATC, e todas estavam relacionadas às condições econômicas e sociais das famílias, e também aos objetivos da própria SATC, ou seja, de amenizar os problemas decorrentes do crescimento econômico da região carbonífera e de formar mão de obra qualificada para atender às necessidades da indústria local.

Como citado anteriormente, a SATC foi criada como Sociedade de Assistência aos Trabalhadores do Carvão. Por isso estudavam, na escola, filhos dos trabalhadores das minas de carvão, que eram beneficiados com bolsas de estudo subsidiadas pelos próprios mineradores. Tal benefício, sem sombra de dúvidas, foi o que levou muitos meninos e, posteriormente, meninas, incentivados por seus pais, a estudarem na instituição, como revelam as depoentes. A concessão das bolsas por parte das mineradoras foi algo que determinou sobremaneira a entrada das exalunas na SATC, como revela Rita ${ }^{3}$ : "Na época, meu pai era mineiro, a gente tinha desconto". Este fato leva a refletir sobre a condição de vida das famílias mineiras na região. Apesar da ideia recorrente de que mineiro ganhava bem, as condições materiais das famílias, geralmente compostas por muitos membros, não era assim tão boa.

As regras na escola já demonstravam rigidez e vigilância, o que permite afirmar que, com a entrada das alunas, no que diz respeito às regras, em quase nada se modificou; porém, não aconteceu o mesmo com relação à vigilância, pois os Irmãos Maristas foram muito categóricos quando defenderam a resistência à entrada das mulheres na escola.

\footnotetext{
${ }^{3}$ Rita de Cássia Dal Bó - nascida em 31 de março de 1959, em Siderópolis, filha de Rubens Dal Bó e Enedina de Oliveira Dal Bó. Entrevista concedida a Jucélia da Silva Abel em 20/07/2010, Vila São João/Criciúma.
} 
Por se tratar de um diretor da Congregação Marista, com uma formação voltada à educação masculina, receber as moças naquele ambiente exigiu providências diferenciadas e a maior delas foi o aumento da vigilância. Esse olhar panóptico ${ }^{4}$ observa e controla os/as alunos/as em todos os momentos na escola. Ele "induz no aluno um estado consciente e permanente de visibilidade, que assegura o funcionamento do poder" (FOUCAULT, 1987, p. 166).

Ivanete ${ }^{5}$ relata: "O Ir. Walmir andava sempre atrás [...] com a nossa entrada na escola ele ficou com medo, ele cuidava da gente, ele cuidava com medo de nos perder, pois a SATC era grande". Segundo ela, "bastava um olhar dele, e thuc, thuc, todos se espalhavam".

Foram diversos os mecanismos de vigilância colocados em prática no cotidiano da Escola Técnica General Osvaldo Pinto da Veiga, uns mais explícitos e outros nem tanto. Isso porque a entrada das meninas certamente resultou em preocupações maiores por parte da direção no que se refere à sexualidade, que se transformou em alvo principal de vigilância. Contudo, o poder e a vigilância utilizados para manter o controle e a disciplina não evitou que houvesse transgressões e, utilizando os estudos de Foucault, podemos dizer que onde há poder, há resistência.

A resistência ao poder instituído pela direção da escola técnica da SATC era manifestada pelas transgressões às regras impostas. As ex-alunas relatam algumas delas.

A disciplina era bem rígida, mas a gente sempre dava uma camufladinha. Os horários eram bem rígidos, nós não podíamos ir no internato, a não ser para almoçar, não podia namorar, mas sempre tinha as que namoravam, e o Ir. Walmir andava sempre atrás. Ninguém entregava ninguém, cada uma ficava na sua. Nos intervalos sempre tinha alguém que fumava, era proibido, mas sempre tinha. Os professores não fumavam na sala de aula, mas alguns davam umas saidinhas para fumar. O mais gostoso era ir no laranjal pegar laranjas, era proibido. ${ }^{6}$

Vale ressaltar que, por mais condenável que fosse qualquer manifestação de namoro na escola, ela existia, como relata Rita:

\footnotetext{
${ }^{4}$ O Panóptico de Bentham é a figura arquitetural: na periferia uma construção em anel; no centro, uma torre; esta é vazada de largas janelas que se abrem à face interna do anel; a construção periférica é dividida em celas, cada uma atravessando toda a espessura da construção; elas têm duas janelas, uma para o interior, correspondendo às janelas da torre; outra, que dá para o exterior, permite que a luz atravesse a cela de lado a lado. Basta, então, colocar um vigia na torre central e em cada cela trancar um louco, um doente, um condenado, um operário ou um escolar. Seu efeito mais importante é induzir no detento um estado consciente e permanente de visibilidade que assegura o funcionamento automático do poder (FOUCAULT, 1987, p. 166).

${ }^{5}$ Ivanete Juvêncio Evangelista. nascida em 21 de fevereiro de 1957, em Siderópolis, filha de Manoel João Juvêncio e Maria Gracioso Figueredo Juvêncio. Entrevista concedida a Jucélia da Silva Abel, em 26/07/2010, Mina do Mato/Criciúma.

${ }^{6}$ Idem, Entrevista citada.
} 
Tinha namoro, ah como tinha! Mas era bom. Tanto na sala de aula como fora, com as outras salas. A Marinês casou com um menino da escola. Ele era do terceiro ano, ele não era da nossa sala [...]. O Irmão Walmir não via. Porque era assim, a gente estava ali, às vezes conversando, mas sempre alguém avisava, "lá vem o Irmão", aí saía todo mundo correndo. Ele nunca nos pegou. Às vezes a gente estava sentada, assim, conversando e ele passava, a gente ficava bem quietinha ${ }^{7}$.

Também o cigarro e até mesmo as drogas circulavam entre os alunos e alunas, como conta Maria ${ }^{8}$.

Na nossa época começou a ter droga na escola. Então o que é que acontecia, tinha uns dois, três na sala que usavam droga, rapazes. E a gente tinha aula de oficina, e em toda a aula de oficina eles estavam chapados. E uma amiga nossa até, de Siderópolis, caiu nessa. Então as mulheres, as outras que estudava ali, tanto eu, as outras não tinham coragem de chegar e dizer pra ela assim "Nós não queremos mais saber de ti porque tu tá metida...". Porque naquele tempo isso era um ... $\mathrm{E}$ todo mundo começou a se afastar dela, e eu fui a única que não me afastei dela. Então eu chegava pra ela e eu dizia "Tu larga dessa porcaria" eu dizia pra ela: "Tu não tais vendo que tu tá metida com ele, assim, assim e assim..." eu falava né, e eu dizia "Eu sou a única que estou te dizendo isso, porque as outras, tu pode ver, ninguém mais quer ficar contigo". Eu era a única que dava em cima dela assim, pra ela largar daquilo. Era maconha. Cigarro nós fumávamos, mas ela fumava maconha e na sala de aula, na hora que a gente tinha intervalo. Ninguém pegou. Os professores sabiam. Então era na aula de oficina, antes da aula de oficina que se aproveitavam. Então o professor mesmo sabia que eles estavam chapados em cima das máquinas e era perigoso e tudo. É, isso aí acontecia lá, na SATC.

As ex-alunas afirmam que, algumas vezes, durante o curso, gazearam as aulas. Rita conta que gazeou umas duas vezes: “Eu peguei e disse, 'vou-me embora, eu não vou ficar aqui'; aí, junto com o pessoal das cinco eu me joguei, mas eu nunca carreguei ninguém atrás de mim, sempre sozinha. Chegava em casa, dava uma desculpa qualquer pra mãe 'Ah, mãe! O professor não veio, liberaram nós'”. Diante disso, fica perceptível que as alunas também transgrediam, portanto, quebravam a ideia de meninas comportadas.

Para Foucault (1979):

Não se pode tomar o poder como um fenômeno de dominação maciço e homogêneo de um indivíduo sobre os outros, de um grupo sobre os outros, de uma classe sobre as outras; mas ter bem presente que o poder - desde que não seja considerado de muito longe - não é algo que se possa dividir entre aqueles que o possuem e o detêm exclusivamente e aqueles que não o possuem e lhe são

\footnotetext{
${ }^{7}$ Rita de Cássia Dal Bó. Entrevista citada.

${ }^{8}$ Maria. Nascida em dezembro de 1955. Entrevista concedida a Jucélia da Silva Abel em 26/07/2010, Criciúma (não revelou demais dados).
} 
submetidos. O poder deve ser analisado como algo que circula, ou melhor, como algo que só funciona em cadeia. Nunca está localizado aqui ou ali, nunca está nas mãos de alguns, nunca é apropriado como uma riqueza ou um bem. $O$ poder funciona e se exerce em rede. Nas suas malhas os indivíduos não só circulam, mas estão sempre em posição de exercer este poder e de sofrer sua ação; nunca são o alvo inerte ou consentimento do poder, são sempre centros de transmissão. Em outros termos, o poder não se aplica aos indivíduos, passa por eles. (FOUCAULT, 1979, p. 183).

Para o autor, qualquer relação social encerra em si, possivelmente, uma relação de poder. As relações de poder que produz o sujeito como seu efeito é inevitável, mas tão inevitável quanto são as relações de resistência, pois onde há poder, há sempre focos de resistência e vice-versa.

A relação das primeiras alunas com os professores e colegas foi contemplada por discriminações e indiferenças, mesmo que não evidenciada por todas as ex-alunas, Maria ${ }^{9}$ fala da professora de Matemática da seguinte forma "[...] era nosso carrasco. [...] ela era assim, pra nós mulheres ela era uma peste [...] ela era dureza com nós, só era boazinha para os rapazes. Nós mulheres éramos discriminadas por ela".

Isso remete à discriminação da própria mulher. Rabelo diz que há mulheres que, quando assumem funções de comando, elas próprias reproduzem segregação, discriminação, assumindo uma postura masculina. "São antissolidárias e agem como se não fossem também atingidas por medidas discriminatórias, tanto na ocupação de seus postos quanto no meio social" (RABELO, 1997, p. 151).

Tal professora mostrava ser mais atenciosa com os meninos do que com as meninas, demonstrando não aceitar a presença das mulheres naquele espaço, até então, masculino. A construção social e cultural em que a professora fora inserida foi determinante para tal atitude. Já com os colegas, tinham uma relação tranquila. Era uma relação voltada aos encantos da sexualidade, elas paqueravam e namoravam muito, motivo pelo qual os Irmãos Maristas intensificaram a vigilância.

Quanto aos professores homens, Ivanete ${ }^{10}$ comenta que "eram bons, mas tinha os que não eram nada simpáticos, tinha engenheiros, eram legais e simpáticos, mas às vezes gozadores da cara da gente, talvez porque não acreditavam em nós, talvez por ser mulher [sic] ou, também, porque tinha muito homens, rapazes, e por nós sermos as primeiras".

\footnotetext{
${ }^{9}$ Maria. Entrevista citada.

${ }^{10}$ Ivanete Juvêncio Evangelista. Entrevista citada.
} 
Receber as primeiras alunas não foi tarefa das mais fáceis, também para os professores, uma vez que estavam acostumados com salas de aula compostas somente por meninos.

Já com relação ao tratamento recebido pelos professores, Rita $^{11}$ comenta que:

Era tudo igual. Não tinha assim, porque é mulher, ah vamos aliviar pra elas. Não tinha nada disso. Eles não se arreganhavam muito pra gente não. Até me lembro de que o professor Joel, ele dava Mecânica Técnica, no segundo ano, assim que a gente entrou, ele ficou assim meio constrangido com as meninas, porque éramos só nós. Um dia ele perguntou "Que idade vocês têm?", porque eu tinha, na época, 15 anos, e as outras já eram mais velhas, ele disse "Ah então é tudo velha já, então eu posso falar besteira".

Este depoimento remete para um dos principais desafios enfrentados pelos professores com a entrada das primeiras alunas, ou seja, a forma de se comunicar em sala de aula. Iraíde ${ }^{12}$ afirma que: "houve mudança até no linguajar, uma sala só com homens é diferente de uma sala com meninas, até os professores mudaram a forma de falar, a postura, teve alguns professores que não gostaram, mas com o tempo, aceitaram".

No que se refere à relação com a direção, as ex-alunas só mantinham contato com o Ir. Walmir que, como já mencionamos, era quem circulava pela escola em constante vigilância. As palavras de Ivanete ${ }^{13}$ confirmam: "Lembro do Ir. Walmir, da Graça, mas não tínhamos contato com ela. Eu lembro bem da nossa orientadora, que era meio Psicóloga, a Dalva". Podemos observar o total desconhecimento dos demais diretores.

Sobre a relação com os meninos da escola, as ex-alunas são unânimes em dizer que foi muito boa. Sonia ${ }^{14}$ relata que "Era bem boa, a gente se ajudava. Na minha turma tinha mais de 20 meninos, bem mais. Era bem normal, como qualquer outra escola, de meninos e meninas. Eles não faziam gracinha. Respeitavam a gente". Ivanete ${ }^{15}$ confirma: "A relação com os meninos era ótima, talvez porque meninos e meninas se entrosem melhor".

Por se tratar de alunos que estavam na faixa etária entre 15 e 17 anos, pode-se dizer que esse entrosamento colocava em jogo a questão da Sexualidade. Para Foucault (1998), “a sexualidade é uma interação social, uma vez que se constitui historicamente a partir de múltiplos

\footnotetext{
${ }^{11}$ Rita de Cássia Dal Bó. Entrevista citada.

${ }^{12}$ Iraíde Antonio Piovesan. Nascido em 17 de janeiro de 1949, em Urussanga, filho de Mário de Bona Sartor Piovesan e Dozolina Cadorin Piovesan. Entrevista concedida a Jucélia da Silva Abel, em 5/04/2010, na SATC, Criciúma-SC. Entrou na SATC como aluno em 1965, fazendo dois cursos de aprendizagem e, posteriormente, o curso técnico de Eletromecânica, permanecendo na escola e no internato por sete anos. Em 1974 entrou na SATC como professor. Atualmente, é Diretor de Relações Cooperativas da SATC.

${ }^{13}$ Ivanete Juvêncio Evangelista. Entrevista citada.

${ }^{14}$ Sonia Maria Rocha Colombo. Nascida em 21 de fevereiro de 1957, em Siderópolis, filha de Manoel João Juvêncio e Maria Gracioso Figueiredo Juvêncio.

${ }^{15}$ Ivanete Juvêncio Evangelista. Entrevista citada.
} 
discursos sobre sexo; discursos que regulam, que normatizam e instauram saberes que produzem verdades." (FOUCAULT 1998, p.12)

$\mathrm{Na}$ adolescência, tudo está em ebulição. Trata-se de um momento em que desperta naturalmente o interesse pela conquista, pela sedução e pelo sexo; é, portanto, natural que alunos e alunas se relacionem com mais intensidade, principalmente num ambiente escolar, onde permanecem por um período bastante longo, que foi o caso dos alunos e alunas da SATC, que permaneciam na escola por período integral.

Neste sentido, Cruz e Oliveira (2002) destacam:

$\mathrm{Na}$ adolescência a maturidade biológica e sexual é atingida e se define, por conseguinte, a identidade sexual, e onde se define o espaço social de homem ou de mulher. Outrossim, para falar sobre sexualidade na adolescência, não se pode apenas referir às questões voltadas à identidade sexual, mas sim a todas as implicações psicossociais que estão associadas. A sexualidade do adolescente implica, principalmente, na convivência com o corpo, com a mente e com as pessoas de sua relação. (CRUZ E OLIVEIRA, 2002, p. 59).

Isso se confirma nas palavras de Maria $^{16}$ : "A gente era bem amiga. O pessoal da turma, assim, a gente era bem amigo. Tanto é que eu namorava um menino, na época, da minha sala". Rita também fala sobre as paqueras: "Tinha, como tinha! Mas era bom. Tanto na sala de aula como fora, com as outras salas. A Marinês casou com um menino da escola. Seu nome era Dalton, eu acho. Ele era do terceiro ano, ele não era da nossa sala. Acho que ele já estava no terceiro da Eletrotécnica, eu acho. Eu sei que os dois casaram".

Utilizando as palavras de Auad (2004), podemos inferir que "a escola é um espaço especialmente marcado pelas relações de Gênero". (AUAD, 2004, p. 1).

A disciplina de desenho foi a grande vilã para as mulheres, o que serviu como chamariz para a entrada no curso de Mecânica opção para o desenho, já que o desenho era considerado uma habilidade feminina, transformou-se, durante o curso, em motivo de reprovação e desistência.

Mesmo com o discurso de que as mulheres tinham o mesmo rendimento que os homens e que o mercado estava absorvendo a mão de obra feminina, constatamos que havia restrições quanto às vagas e funções dos estágios. A escola não ofereceu um local para que elas estagiassem, como acontecia com os meninos, elas é que foram em busca. E quando foram para as empresas,

\footnotetext{
${ }^{16}$ Maria. Entrevista citada.
} 
suas funções eram restritas, não tinham acesso ao processo produtivo, a divisão sexual do trabalho e a desigualdade de gênero era facilmente evidenciada.

A entrada das primeiras alunas na Escola Técnica SATC, não foi um processo natural, como afirmam os gestores e as próprias alunas, pois havia resistências e um histórico de reivindicações e de lutas, pois, mesmo com a inserção das mulheres no mercado de trabalho formal, a desigualdade era visível, principalmente quanto à questão salarial.

Diante disso, podemos dizer que a invasão das mulheres na Escola Técnica da SATC, um espaço predominantemente masculino, mesmo cercado por barreiras, transgressões, resistências, restrições e desigualdades, significou, para as mulheres e para a sociedade, um avanço no que diz respeito às relações de gênero.

Foi um processo de rupturas acompanhado por conflitos, que abriu as portas para outras mulheres.

\section{REFERÊNCIAS}


AUAD, Daniela. Relações de Gênero nas práticas escolares: da escola mista ao ideal de coeducação. Tese (Doutorado em Educação, área de Sociologia da Educação), São Paulo, Faculdade de Educação da Universidade de São Paulo, 2004.

CAROLA, Carlos Renato. Dos subterrâneos da história: as trabalhadoras das minas de carvão de Santa Catarina. Florianópolis: Ed. da UFSC, 2002.

CRUZ, Ana Claudia Neves; OLIVEIRA, Silvia Michele Paiva de. Sexualidade do adolescente: um novo olhar sem mitos e preconceitos. Trabalho de conclusão de curso. Curso de pedagogia. Universidade da Amazônia - UNAMA. Belém. Pará, 2002.

FOUCAULT, Michel. Microfísica do poder. Organização e tradução de Roberto Machado. Rio de Janeiro: Edições Graal, 1979.

História da sexualidade I: a vontade do saber. Rio de Janeiro: Edições Graal, 1998.

. Vigiar e punir: História das violências nas prisões. Trad. Raquel Ramalhete. 22 ed. Petrópolis, Vozes: 1987.

KENSKI, Vani Moreira. Sobre o conceito de memória. In: FAZENDA, Ivani Catarina Arantes. (Org.) Campinas, SP: Papirus, 1995. p. 137 - 159. A pesquisa em educação e as transformações do conhecimento.

LOURO, Guacira Lopes. Nas redes do conceito de gênero. In: LOPES, MEYER, D.E.; WALDOW, V.R. Gênero e Saúde. Porto Alegre: Artes Médicas, 1996. Disponível em: <www.ufrgs.br/geerge/redes.htm>. Acesso em: 08 Fevereiro 1998.

Gênero, sexualidade e educação: uma perspectiva pós-estruturalista. Petrópolis: Ed. Vozes, 1997-2003-2006.

LUSTOSA, Maria Anita Vieira. A inserção da mulher na esfera produtiva: uma leitura de gênero, trabalho e educação. Dissertação (mestrado). Universidade Federal do Ceará, Faculdade de Educação, Programa de Pós-graduação em Educação Brasileira, Fortaleza (CE), 2009. Disponível em: <www.teses.ufs.br/busca/arquivo.php?cosArquivo=3976>. Acesso em: 19 Março 2011.

MEIHY, Jose Carlos Sebe Bom. Manual da história oral. 5 ed. São Paulo: Edições Loyola, 2005.

RABELO, Giani. Trabalho arcaico no moderno mundo da moda. 1997. (Dissertação) Florianópolis: Universidade Federal de Santa Catarina. Programa de Pós-Graduação em Educação, 1997.

RECEBIDO EM 12 DE SETEMBRO DE 2012

APROVADO EM 01 DE DEZEMBRO DE 2012 